\title{
Evaluasi Obat Kadaluwarsa, Obat Rusak dan Stok Mati di Puskesmas Wilayah Magelang
}

Revina Nurma Khairani, Elmiawati Latifah*, Ni Made Ayu Septiyaningrum

Program Studi Farmasi, Fakultas Ilmu Kesehatan, Universitas Muhammadiyah Magelang, Magelang, Indonesia

*Corresponding author: elmiawatilatifah@ummgl.ac.id

Submitted: 7 Juli 2020

Accepted: 15 September 2020

Published: 27 April 2021

\begin{abstract}
Background: In the era of National Health Insurance, drug management problems in health centers still often occur, so it is necessary to carry out a continuous evaluation to ensure optimal availability and service of drugs. Objective: This study aims to describe and analyze the occurrence of expired drugs, damaged drugs, and dead stocks, to provide policy recommendations for improving drug management. Methods: Non-experimental research with analytical descriptive design, which is analyzed descriptively and qualitatively. The sample used to evaluate expired and damaged drugs is all drugs in 2019, while the sample for evaluation of dead stock uses a combination of indicator drugs and e-catalog drugs that are the most consumed in 2019. Factors that affect barriers to drug management are observed by interview. Result: The expired drugs at Puskesmas $X$ and $Y$ were $24 \%$ and $18 \%$, dead stock was $40 \%$ and 20\%, no damaged drugs were found in the two health centers. The problem of drug management that dominantly occurs in puskesmas is due to a factor in changing prescribing patterns, expiration dates that are too short and the unsatisfactory demand for drugs received from the UPT Pharmacy Installation. Conclusion: The percentage of expired drugs and dead stock drugs is not following the research indicators (0\%), so with these findings, it is necessary to validate drug planning according to drug needs as well as improve management of expired drug management and strengthening the drug acceptance system at the health center.
\end{abstract}

Keywords: drug management, deadstock, expired drugs, damaged drugs, health center

\begin{abstract}
Abstrak
Pendahuluan: Di era Jaminan Kesehatan Nasional, masalah pengelolaan obat di puskesmas masih sering terjadi sehingga perlu dilakukan evaluasi yang berkelanjutan untuk menjamin ketersediaan dan pelayanan obat yang optimal. Tujuan: Penelitian ini bertujuan untuk mengetahui gambaran dan menganalisis terjadinya obat kadaluwarsa, obat rusak dan stok mati, sehingga dapat memberikan rekomendasi kebijakan untuk perbaikan pengelolaan obat. Metode: Penelitian non eksperimental dengan rancangan deskriptif analisis, yang dianalisis secara deskriptif dan kualitatif. Sampel yang digunakan untuk mengevaluasi obat kadaluwarsa dan obat rusak adalah seluruh obat tahun 2019, sedangkan sampel untuk evaluasi stok mati menggunakan kombinasi obat indikator dan obat e-katalog yang paling banyak dikonsumsi pada tahun 2019. Faktor yang mempengaruhi hambatan pengelolaan obat dilakukan observasi dengan wawancara. Hasil: Obat kadaluwarsa di Puskesmas X dan Y sebesar $24 \%$ dan 18\%, stok mati sebesar $40 \%$ dan $20 \%$, tidak ditemukan obat rusak di kedua puskemas. Masalah pengelolaan obat yang dominan terjadi di puskesmas, disebabkan adanya faktor perubahan pola peresepan, tanggal kadaluwarsa yang terlalu pendek dan tidak sesuainya permintaan dengan penerimaan obat dari UPT Instalasi Farmasi. Kesimpulan: Persentase obat kadaluwarsa dan obat stok mati belum sesuai dengan indikator penelitian $(0 \%)$, sehingga dengan temuan ini perlu dilakukan validasi perencanaan obat yang disesuaikan dengan kebutuhan obat serta peningkatan manajemen pengelolaan obat kadaluwarsa dan penguatan sistem penerimaan obat di puskesmas.
\end{abstract}

Kata kunci: pengelolaan obat, stok mati, obat kadaluwarsa, obat rusak, puskesmas 


\section{PENDAHULUAN}

Proses pengelolaan obat di puskesmas merupakan salah satu hal penting yang harus diperhatikan, karena apabila pengelolaan obat tidak sesuai dengan prosedur akan menimbulkan masalah tumpang tindih anggaran serta pemakaian obat yang tidak tepat. Hal tersebut mengakibatkan ketersediaan obat menjadi berkurang, obat menumpuk karena perencanaan obat yang tidak sesuai, serta biaya obat menjadi mahal karena penggunaan obat yang tidak rasional (Nurniati dkk., 2016). Selain itu, dampak akibat perencanaan yang tidak sesuai menyebabkan tempat penyimpanan obat menjadi penuh sehingga obat berisiko menjadi kadaluwarsa, rusak hingga stok mati.

Salah satu ruang lingkup pengelolaan obat adalah penyimpanan obat. Proses penyimpanan obat yang tidak sesuai dapat menimbulkan kerugian seperti tidak dapat mempertahankan mutu dari sediaan obat sehingga obat menjadi kadaluwarsa sebelum tanggalnya tiba (Akbar dkk., 2016). Pelayanan obat dapat berjalan baik dan tepat jika didukung penyimpanan obat yang sesuai (Somantri, 2013).

Hasil dari penelitian sebelumnya yang dilakukan di Puskesmas wilayah Magelang, menyatakan bahwa persentase stok mati sebesar 9\%, obat kadaluwarsa sebesar 4\% dengan nilai kerugian sebesar Rp. 2.903.954 dan obat rusak sejumlah $0 \%$. Hal ini disebabkan karena berubahnya pola peresepan dokter dan tidak terdapat jenis penyakit yang menggunakan obat tersebut sehingga tidak mengalami pengeluaran (Oktafiyana, 2019).

Penelitian ini bertujuan untuk mengetahui perbedaan pengelolaan obat kadaluwarsa, rusak dan stok mati di antara kedua puskesmas di wilayah Magelang dengan perbedaan setting di Kabupaten dan Kota Magelang, yang juga terdapat perbedaan ketersediaan Sumber Daya Manusia (SDM) apoteker sebagai salah satu support system dalam siklus pengelolaan obat. Sampel yang digunakan menggunakan kombinasi obat indikator dan obat e-katalog yang paling banyak dikonsumsi pada tahun 2019, sehingga dapat mengetahui gambaran penggunaan obat e-katalog yang paling banyak dikonsumsi di puskesmas dan dapat memberikan pertimbangan Rencana Kebutuhan Obat (RKO) periode selanjutnya. Selain itu, penelitian ini juga bertujuan untuk menganalisis penyebab terjadinya obat ED dan rusak serta stok mati agar dapat menjadi rekomendasi kebijakan untuk perbaikan pengelolaan obat.

\section{BAHAN DAN METODE}

\section{Bahan}

Bahan yang digunakan dalam penelitian ini yaitu dokumen berita acara obat kadaluwarsa dan obat rusak tahun 2019 untuk mendapatkan data terkait obat kadaluwarsa dan rusak, kartu stok obat untuk mendapatkan data konsumsi obat serta dokumen stok opname tahun 2019 untuk mengetahui keseluruhan jumlah obat yang tersedia, yang digunakan untuk menganalisis stok mati.

\section{Alat}

Lembar observasi obat kadaluwarsa, obat rusak dan stok mati merupakan instrument dalam penelitian. Selain observasi data sekunder, juga dilakukan wawancara dengan petugas kefarmasian di kedua puskesmas untuk mengetahui penyebab obat ED, rusak dan stok mati di puskesmas.

\section{Metode \\ Desain penelitian}

Jenis penelitian pada ini merupakan penelitian non eksperimental dengan rancangan deskriptif analisis, yang dianalisis secara deskriptif dan kualitatif.

\section{Populasi dan sampel}

Populasi pada penelitian ini adalah seluruh obat di Puskesmas X Kota Magelang dan Puskesmas Y Kabupaten Magelang tahun 2019. Sampel yang digunakan untuk mengevaluasi obat kadaluwarsa dan obat rusak adalah seluruh obat di Puskesmas X Kota Magelang dan Puskesmas Y Kabupaten Magelang tahun 2019, sedangkan sampel untuk evaluasi obat stok mati menggunakan kombinasi obat indikator dan obat ekatalog yang paling banyak dikonsumsi pada tahun 2019. Daftar obat indikator yang digunakan dalam penelitian ini berdasarkan Petunjuk Teknis Tata Laksana Indikator Kinerja Tata Kelola Obat Publik dan Perbekalan Kesehatan Tahun 2017 - 2019 (Kemenkes RI, 2017).

\section{Pengumpulan data}

Pengumpulan data pada penelitian ini dilakukan dengan observasi pada data sekunder, yang terdiri dari data obat kadaluwarsa, rusak pada berita acara puskesmas dan data konsumsi obat pada tahun 2019 untuk menganalisis stok mati.

\section{Analisis data}

Analisis data dalam penelitian ini adalah analisis data deskriptif dan kualitatif. Data yang diperoleh kemudian dihitung menggunakan rumus. Hasil yang dipereroleh berupa persentase kemudian dibandingkan dengan indikator penelitian. Berikut rumus yang digunakan dalam perhitungan data, yaitu: 


\section{Persentase obat kadaluwarsa}

Data diperoleh dengan menghitung jumlah obat obat yang telah melewati masa pakai atau masa kadaluwarsanya (A) dibagi dengan jumlah obat yang tersedia pada tahun 2019 (B). Indikator obat kadaluwarsa yaitu $0 \%$.

$$
\% \text { obat kadaluwarsa }=\frac{(A)}{(B)} \times 100 \%
$$

\section{Persentase obat rusak}

Data diperoleh dengan menghitung jumlah obat yang mengalami kerusakan pada tahun 2019 (A) dibagi dengan jumlah obat yang tersedia pada tahun 2019 (B). Indikator obat rusak yaitu $0 \%$.

$$
\% \text { obat rusak }=\frac{(A)}{(B)} \times 100 \%
$$

\section{Persentase stok mati}

Data diperoleh dengan menghitung jumlah obat yang mengalami dead stock atau obat yang tidak terdapat pengeluaran selama 3 bulan (A) dibagi dengan jumlah kombinasi antara obat indikator dan obat e-katalog (B). Indikator stok mati yaitu $0 \%$.

$$
\% \text { obat dead stock }=\frac{(A)}{(B)} \times 100 \%
$$

\section{HASIL DAN PEMBAHASAN}

Berdasarkan data yang diperoleh kemudian dilakukan analisis maka diperoleh hasil sebagai berikut:

\section{Obat kadaluwarsa}

Obat kadaluwarsa adalah obat yang telah melewati masa pakai atau masa kadaluwarsanya (Management Science Health, 2012). Tujuan melakukan evaluasi obat kadaluwarsa yaitu untuk mengetahui besarnya nilai kerugian akibat obat. Berdasarkan penelitian yang telah dilakukan diperoleh hasil persentase obat kadaluwarsa pada puskesmas $\mathrm{X}$ sebesar $24 \%$ dengan total kerugian Rp. 6.530.095,- sedangkan pada puskesmas Y sebesar $18 \%$ dengan total kerugian Rp. 14.338.834,- (Tabel 1

\begin{tabular}{|c|c|c|c|c|c|}
\hline No. & Nama Obat & $\begin{array}{c}\text { Tanggal } \\
\text { Kadaluwarsa }\end{array}$ & Jumlah & $\begin{array}{l}\text { Harga Satuan } \\
\text { (Rupiah) }\end{array}$ & $\begin{array}{c}\text { Total } \\
\text { (Rupiah) }\end{array}$ \\
\hline 1. & Cimetidin & Agu-19 & 149 tablet & Rp. 19 & Rp. 2.773 \\
\hline 2. & Candesartan $8 \mathrm{mg}$ & Nov-19 & 7 tablet & Rp. 519 & Rp. 3.633 \\
\hline 3. & Vit A 100.000 & Jun-19 & 13 kapsul & Rp. 284 & Rp. 3.693 \\
\hline 4. & Spironolacton & Agu-19 & 21 tablet & Rp. 244 & Rp. 5.124 \\
\hline 5. & Piridoksin HCL & Jul-19 & 193 tablet & Rp. 45 & Rp. 8.685 \\
\hline 6. & Aminofilin & Jul-19 & 104 tablet & Rp. 94 & Rp. 9.776 \\
\hline 7. & Isoniazid $100 \mathrm{mg}$ & Sep-19 & 405 tablet & Rp. 25 & Rp. 10.125 \\
\hline 8. & Loperamide & Jun-19 & 180 tablet & Rp. 85 & Rp. 15.300 \\
\hline 9. & Asam retionoat $0,1 \%$ & Apr-19 & 3 tube & Rp. 9.759 & Rp. 29.277 \\
\hline 10. & Ergotamin & Feb-19 & 194 tablet & Rp. 167 & Rp. 32.398 \\
\hline 11. & Metformin 850 & Mei-19 & 196 tablet & Rp. 198 & Rp. 38.710 \\
\hline 12. & Spironolactone $250 \mathrm{mg}$ & Nov-19 & 149 tablet & Rp. 294 & Rp. 43.806 \\
\hline 13. & Ergotamin & Okt-19 & 302 tablet & Rp. 173 & Rp. 52.246 \\
\hline 14. & Inerson salep & Sep-19 & 6 tube & Rp. 10.000 & Rp. 60.000 \\
\hline 15. & Glimepiride 4 mg & Nov-19 & 229 tablet & Rp. 270 & Rp. 61.830 \\
\hline 16. & Amoxicillin $250 \mathrm{mg}$ & Agu-19 & 317 kapsul & Rp. 211 & Rp. 66.887 \\
\hline 17. & Urinter & Okt-19 & 50 tablet & Rp. 1.400 & Rp. 70.000 \\
\hline 18. & Bisoprolol $5 \mathrm{mg}$ & Agu-19 & 320 tablet & Rp. 236 & Rp. 75.520 \\
\hline 19. & Kotrimoksazol $480 \mathrm{mg}$ & Agu-19 & 602 tablet & Rp. 129 & Rp. 77.658 \\
\hline 20. & Dulcolax suppositoria & Jan-19 & 16 butir & Rp. 4.990 & Rp. 79.840 \\
\hline 21. & Ephinefrin injeksi & Jun-19 & 10 ampul & Rp. 8.100 & Rp. 81.000 \\
\hline 22. & Oxytocin injeksi & Nov-19 & 43 ampul & Rp. 1.900 & Rp. 81.700 \\
\hline 23. & Stesolid rectal $10 \mathrm{mg}$ & Sep-19 & 5 tube & Rp. 18.279 & Rp. 91.395 \\
\hline 24. & Asam retinoat salp & Nov-19 & 10 pcs & Rp. 9.759 & Rp. 97.590 \\
\hline 25 . & Fitomenadion injeksi & Agu-19 & 30 ampul & Rp. 3.550 & Rp. 106.500 \\
\hline 26. & Acetilsistein & Sep-19 & 270 tablet & Rp. 426 & Rp. 115.020 \\
\hline 27. & Zinc sirup & Jun-19 & 21 botol & Rp. 6.600 & Rp. 138.600 \\
\hline 28. & Amoxicillin sirup & Feb-19 & 69 botol & Rp. 2.090 & Rp. 144.210 \\
\hline 29. & Metronidazol sirup & Agu-19 & 38 botol & Rp. 3.950 & Rp. 150.100 \\
\hline 30. & Stesolid rectal $5 \mathrm{mg}$ & Jul-19 & 14 tube & Rp. 12.090 & Rp. 169.260 \\
\hline 31. & Cefixime sirup & Jun-19 & 29 botol & Rp. 6.150 & Rp. 178.350 \\
\hline 32. & Kotrimoksazol 240 syr & Nov-19 & 79 botol & Rp. 2.286 & Rp. 180.594 \\
\hline 33. & Lamivudine-zidovudine & Nov-19 & 60 tablet & Rp. 3.700 & Rp. 222.000 \\
\hline
\end{tabular}
dan Tabel 2).

Tabel 1. Obat kadaluwarsa di puskesmas $X$ 


\begin{tabular}{|c|c|c|c|c|c|}
\hline 34. & Hiosin plus & Sep-19 & 150 tablet & Rp. 1.500 & Rp. 224.994 \\
\hline 35 . & Kloramfenicol sirup & Jul-19 & 75 botol & Rp. 3.955 & Rp. 296.625 \\
\hline 36. & Candesartan $16 \mathrm{mg}$ & Agu-19 & 318 tablet & Rp. 1.122 & Rp. 356.796 \\
\hline 37. & Pyrantel sirup & Des-19 & 41 botol & Rp. 9.700 & Rp. 397.700 \\
\hline 38. & Nerilon cream & Apr-19 & 40 tube & Rp. 12.250 & Rp. 490.000 \\
\hline 39. & OAT anak & Jul-19 & 3 pack & Rp. 195.442 & Rp. 586.326 \\
\hline 40. & Kotrimoksazol syr $240 \mathrm{mg}$ & Jul-19 & 314 botol & Rp. 2.286 & Rp. 717.804 \\
\hline 41. & Efavirens & Jun-19 & 150 tablet & Rp. 6.375 & Rp. 956.250 \\
\hline \multicolumn{5}{|c|}{ Total keseluruhan } & Rp. 6.530 .095 \\
\hline
\end{tabular}

Sumber: Data Sekunder Puskesmas X (2019)

Tabel 2. Obat kadaluwarsa di puskesmas $Y$

\begin{tabular}{|c|c|c|c|c|c|}
\hline No. & Nama Obat & $\begin{array}{c}\text { Tanggal } \\
\text { Kadaluwarsa }\end{array}$ & Jumlah & $\begin{array}{l}\text { Harga Satuan } \\
\text { (Rupiah) }\end{array}$ & Total (Rupiah) \\
\hline 1. & Betahistin & Agu-19 & 24 tablet & Rp. 149 & Rp. 3.576 \\
\hline 2. & Cefadroxil sirup & Feb-19 & 6 botol & Rp. 3.922 & Rp. 23.532 \\
\hline 3. & Scabimite ZK & Mei-19 & 3 tube & Rp. 12.155 & Rp. 36.465 \\
\hline 4. & Ictyol zk & Agu-19 & 31 butir & Rp. 2.150 & Rp. 66.650 \\
\hline 5. & Kotrimoxazole syr & Nov-19 & 33 botol & Rp. 2.286 & Rp. 75.438 \\
\hline 6. & Phenobarbital & Nov-19 & 1375 tablet & Rp. 56 & Rp. 77.000 \\
\hline 7. & Clobazam & Sep-19 & 90 tablet & Rp. 900 & Rp. 81.000 \\
\hline 8. & Lexapram sirup & Sep-19 & 43 botol & Rp. 2.530 & Rp. 108.790 \\
\hline 9. & Povidum iodium & Sep-19 & 8 butir & Rp. 17.996 & Rp. 143.968 \\
\hline 10. & CPZ $100 \mathrm{mg}$ & Nov-19 & 1068 tablet & Rp. 147 & Rp. 156.996 \\
\hline 11. & Kotrimoxazole sirup & Mei-19 & 70 botol & Rp. 2.286 & Rp. 160.020 \\
\hline 12. & Besi sulfat & Sep-19 & 640 botol & Rp. 352 & Rp. 225.280 \\
\hline 13. & Lisinopril 5 mg & Mar-19 & 918 tablet & Rp. 269 & Rp. 246.942 \\
\hline 14. & Amoxicillin sirup & Jun-19 & 132 botol & Rp. 1.881 & Rp. 248.292 \\
\hline 15. & Gluquidon & Agu-19 & 300 tablet & Rp. 1.075 & Rp. 322.500 \\
\hline 16. & Sucrafat sirup & Mar-19 & 43 botol & Rp. 8.338 & Rp. 358.534 \\
\hline 17. & Scabimite ZK & Sep-19 & 33 ampul & Rp. 11.825 & Rp. 390.225 \\
\hline 18. & ATS 1500 & Apr-19 & 3 ampul & Rp. 130.999 & Rp. 392.997 \\
\hline 19. & Domperidon & Sep-19 & 152 botol & Rp. 3.000 & Rp. 456.000 \\
\hline 20. & Lisinopril $10 \mathrm{mg}$ & Mar-19 & 1500 tablet & Rp. 310 & Rp. 465.000 \\
\hline 21. & Vit B6 & Mei-19 & 4029 tablet & Rp. 118 & Rp. 475.422 \\
\hline 22. & Zinc tab & Des-19 & 1100 tablet & Rp. 513 & Rp. 564.300 \\
\hline 23. & Griseofulvin & Mar-19 & 2500 tablet & Rp. 247 & Rp. 617.500 \\
\hline 24. & Vit K & Mei-19 & 977 tablet & Rp. 691 & Rp. 675.107 \\
\hline 25. & Kotrimoxazole sirup & Apr-19 & 350 botol & Rp. 2.286 & Rp. 800.100 \\
\hline 26. & $\mathrm{ABU}$ & Apr-19 & 4 ampul & Rp. 462.000 & Rp. 1.848 .000 \\
\hline 27. & Kloramp TT & Okt-19 & 356 butir & Rp. 6.600 & Rp. 2.349 .600 \\
\hline 28. & Kanina sirup & Sep-19 & 512 botol & Rp. 5.800 & Rp. 2.969 .600 \\
\hline \multicolumn{5}{|c|}{ Total keseluruhan } & Rp. 14.338.834 \\
\hline
\end{tabular}

Sumber: Data Sekunder Puskesmas Y (2019)

Puskesmas X wilayah Magelang mengalami obat kadaluwarsa yang disebabkan karena obat tidak diresepkan kembali oleh dokter sehingga obat menumpuk di ruang penyimpanan obat dan menjadi kadaluwarsa (sumber : wawancara informan 1). Adapun penyebab dari Puskesmas Y wilayah Magelang karena tanggal kadaluwarsa yang terlalu pendek dan tidak sesuai dengan permintaan serta penerimaan obat dari UPT Instalasi Farmasi (sumber: wawancara informan 2). Dibandingkan dengan hasil penelitian (Sarwijiyati, 2019) di Instalasi Farmasi Kesehatan (IFK) diperoleh persentase obat kadaluwarsa sebesar $1,85 \%$ dengan kerugian sebesar Rp. 18.446.158 yang disebabkan karena rendahnya permintaan dari puskesmas sehingga obat menjadi kadaluwarsa. Berdasarkan analisis tersebut, penyebab obat kadaluwarsa dipengaruhi oleh adanya perubahan pola peresepan dan kurangnya skrinning saat penerimaan obat sehingga didapatkan obat yang diterima memiliki ED yang pendek.

Menurut Satibi (2017), besarnya nilai persentase obat yang kadaluwarsa mencerminkan tidak tepatnya dalam proses perencanaan dan kurang baiknya pengamatan mutu obat dalam proses penyimpanan obat. Standar indikator obat kadaluwarsa adalah $0 \%$ sehingga 
dari hasil penelitian menunjukkan bahwa tidak sesuai dengan indikator yang telah ditetapkan. Banyaknya obat yang mengalami kadaluwarsa dipengaruhi sistem penyimpanan yang kurang tepat serta tidak adanya pencatatan identitas obat yang memadai sehingga distribusi obat tidak efektif (Razak dkk., 2012). Upaya yang dapat dilakukan untuk meminimalisir terjadinya obat kadaluwarsa adalah menggunakan sistem penyimpanan obat secara FIFO (First In First Out) dan FEFO (First Expired First Out) serta memperhatikan pengadaan obat yang disesuaikan dengan kasus yang ada (Purwidyaningrum dkk., 2012).

\section{Obat rusak}

Obat rusak adalah obat yang telah mengalami perubahan mutu seperti berubahnya bau, bentuk, warna dan rasa dari obat. Berdasarkan penelitian yang telah dilakukan di Puskesmas X Kota Magelang dan Puskesmas Y Kabupaten Magelang tidak ditemukan adanya obat rusak dikarenakan penyimpanan obat di Puskesmas X dan Puskesmas Y sudah sesuai dengan standar pelayanan kefarmasian di puskesmas. Data obat rusak diperoleh dari dokumen sekunder puskesmas, yaitu berita acara obat rusak di puskesmas. Tahap penyimpanan obat di Pusekesmas $\mathrm{X}$ menggunakan sistem FIFO (First In First Out) dan FEFO (First Expired First Out), sedangkan di Puskesmas Y menggunakan sistem FIFO (First In First Out). Dibandingkan dengan hasil penelitian (Syahreni, 2016) dengan persentase obat rusak sebesar 54,84\%, disebabkan karena kesalahan pada proses penyimpanan obat dan 45,16\% karena kesalahan pada proses penerimaan obat.

Faktor-faktor yang menyebabkan obat rusak yaitu faktor internal dan faktor eksternal. Faktor internal yaitu perubahan obat secara fisika seperti perubahan bentuk dari obat, perubahan warna atau terdapat partikel asing. Faktor eksternal seperti ruang penyimpanan obat yang tidak sesuai dengan standar yang telah ditetapkan serta sistem penataam obat yang tidak baik (Dyahariesti \& Yuswantina, 2017). Ruang penyimpanan obat dengan sirkulasi udara yang tidak baik dapat mempengaruhi kelembaban udara sehingga obat menjadi cepat rusak (Priyanto dkk., 2010).

\section{Stok mati}

Menurut (Satibi, 2017) stok obat yang tidak digunakan selama 3 bulan atau selama 3 bulan tidak terdapat transaksi disebut sebagai deadstock. Berdasarkan penelitian yang telah dilakukan diperoleh hasil sebagai berikut:

\section{Puskesmas X Magelang}

Berdasarkan hasil yang diperoleh obat yang mengalami stok mati sebanyak 20\%. Berikut jenis obat yang mengalami stok mati :

a. Albendazole, disebabkan karena adanya jenis program baru di puskesmas dengan menggunakan jenis obat albendazole. Kemudian tidak terdapat jadwal program yang menggunakan obat tersebut sehingga tidak mengalami pengeluaran.

b. Amoxicillin sirup, disebabkan karena tidak ada kasus dalam penggunaan obat.

c. Diazepam $5 \mathrm{mg} / \mathrm{m}, 1$ disebabkan karena jenis obat ini baru tersedia di puskesmas sehingga penggunaan dengan jenis obat ini belum terlalu banyak.

d. Fitomenadion, disebabkan perubahan pola peresepan (Sumber: wawancara informan 1).

\section{Puskesmas Y Magelang}

Berdasarkan hasil yang diperoleh obat yang mengalami stok mati sebanyak $40 \%$. Berikut jenis obat yang mengalami stok mati :

a. Albendazole, disebabkan karena belum terdapat jadwal program yang menggunakan obat tersebut sehingga tidak mengalami pengeluaran.

b. Diazepam $5 \mathrm{mg} / \mathrm{ml}$, disebabkan tidak ada kasus dalam penggunaan obat.

c. Fitomenadion, disebabkan karena obat yang diterima memiliki tanggal kadaluwarsa yang terlalu cepat.

d. Furosemid $40 \mathrm{mg}$, disebabkan tidak ada kasus dalam penggunaan obat.

e. Kaptopril, disebabkan tidak ada kasus dalam penggunaan obat.

f. Obat anti TBC dewasa, disebabkan tidak ada kasus dalam penggunaan obat.

g. Tablet tambah darah, disebabkan karena tidak ada jadwal program sehingga tidak mengalami pengeluaran.

h. Vitamin $B_{1}$ disebabkan tidak ada kasus dalam penggunaan obat (Sumber: wawancara informan 2).

Dibandingkan dengan hasil penelitian (Mauliana dkk., 2020), diperoleh persentase stok mati sebesar 3,24\% yang disebabkan karena dokter tidak meresepkan obat lagi dan terdapat kesalahan dalam pengadaan obat sehingga obat menjadi menumpuk. Kerugian yang ditimbulkan akibat adanya stok mati adalah perputaran uang yang tidak lancar dan kerusakan obat akibat terlalu lama disimpan yang menyebabkan obat menjadi 
kadaluwarsa (Satibi, 2017). Terjadinya stok mati disebabkan proses perencanaan dan pengadaan obat yang kurang baik. Perencanaan dan pengadaan obat disesuaikan dengan kebutuhan dan anggaran yang ada berdasarkan jenis, jumlah dan harga perbekalan farmasi (Razak dkk., 2012). Upaya yang dapat dilakukan untuk meminimalisir terjadinya stok mati yaitu pemantauan dan pengawasan terhadap stok obat setiap bulan supaya dapat diketahui obat yang mengalami stok mati (Wati dkk., 2013).

Rekomendasi yang diberikan untuk masalah ini adalah perlu adanya koordinasi perencanaan kebutuhan yang baik antara IFK dan puskesmas, sehingga meningkatkan akurasi perencanaan obat. Selain itu perlu adanya SPO penerimaan obat yang baik, sehingga dapat diantisipasi penerimaan obat-obatan yang memiliki ED pendek. Terkait dengan pola peresepan yang berubah, perlu ditingkatkan adanya koordinasi antara prescriber dan Farmasi terkait perencanaan obat, selain itu mengoptimalkan kombinasi metode perencanaan obat secara konsumsi dan morbiditas sehingga meningkatkan akurasi perencanaan obat. Pengelolaan obat yang lebih baik jika dilihat dari indikator stok mati dan obat kadaluwarsa, terdapat pada puskesmas X. Puskesmas Y belum memiliki Apoteker, hal ini juga dapat berpengaruh terhadap pengelolaan obat yang ada, karena Apoteker sebagai support system pada setiap siklus pengelolaan obat memiliki peran yang critical.

\section{KESIMPULAN}

Obat kadaluwarsa di Puskesmas X dan Y sebesar $24 \%$ dan $18 \%$, obat stok mati sebesar $40 \%$ dan $20 \%$, tetapi tidak ditemukan obat rusak di kedua puskemas. Masalah pengelolaan obat yang dominan terjadi di puskesmas, disebabkan adanya faktor perubahan pola peresepan, tanggal kadaluwarsa yang terlalu pendek dan tidak sesuainya permintaan dengan penerimaan obat dari UPT Instalasi Farmasi. Persentase obat kadaluwarsa dan stok mati tidak sesuai dengan indikator penelitian $(0 \%)$, sehingga dengan temuan ini perlu dilakukan validasi perencanaan obat yang disesuaikan dengan kebutuhan obat serta peningkatan manajemen pengelolaan obat kadaluwarsa dan penguatan sistem penerimaan obat di puskesmas.

\section{DAFTAR PUSTAKA}

Akbar, N. H., Kartinah, N. \& Wijaya, C. (2016). Analisis Manajemen Penyimpanan Obat di Puskesmas Se-Kota Banjarbaru. Jurnal
Manajemen Dan Pelayanan Farmasi; 6; 255260.

Dyahariesti, N. \& Yuswantina, R. (2017). Evaluasi Keefektifan Pengelolaan Obat di Rumah Sakit. Media Farmasi Indonesia; 14; 1485-1492.

Kemenkes RI. (2017). Petunjuk Teknis Tata Laksana Indikator Kinerja Tata Kelola Obat Publik dan Perbekalan Kesehatan Tahun 2017-2019. Jakarta: Direktorat Jenderal Kefarmasian dan Alat Kesehatan Kementerian Kesehatan RI.

Management Sciences for Health. (2012). MDS-3: Managing Access to Medicines and Health Technologies. Arlington: Management Sciences for Health

Mauliana, M., Wiryanto, W. \& Harahap, U. (2020). Evaluation of Drug Management Achievement in Pharmacy Installation of Langsa General Hospital. Asian Journal of Pharmaceutical Research and Development; 8; 5-10.

Nurniati, L., Lestari, H. \& Lisnawaty. (2016). Studi Tentang Pengelolaan Obat di Puskesmas Buranga Kabupaten Wakatobi Tahun 2016. Jurnal Ilmiah Mahasiswa Kesehatan Masyarakat; 1; 1-9.

Oktafiyana, S. (2019). Gambaran Obat Dead Stock, Obat Rusak dan Obat Kadaluwarsa di Puskesmas Salaman I Periode Januari - Juni 2019. Skripsi; Fakultas Ilmu Kesehatan Universitas Muhammadiyah Magelang, Magelang.

Priyanto, A., Hasanmihardja, M. \& Setiawan, D. (2010). Pelaksanaan Penyimpanan Obat dan Pelayanan Informasi Obat Kepada Pasien di Puskesmas di Kota Purwokerto. Jurnal Farmasi Indonesia; 7; 93-106.

Purwidyaningrum, I., Hakim, L. \& Pujitami, S. W. (2012). Evaluasi Efisien Distribusi Obat Rawat Inap di Instalasi Farmasi RSUD Tarakan Jakarta Pusat. Jurnal Manajemen Dan Pelayanan Farmasi; 2; 7-13.

Razak, A., Pamudji, G., \& Harsono, M. (2012). Analisis Efisiensi Pengelolaan Obat Pada Tahap Distribusi dan Penggunaan di Puskesmas. Jurnal Manajemen Dan Pelayanan Farmasi; 2; 186194.

Sarwijiyati, E. (2019). Evaluasi Pengelolaan Obat Kadaluarsa di Instalasi Farmasi Kabupaten (IFK) "Y". Skripsi; Diploma III Farmasi STIKES Duta Gama Klaten, Klaten.

Satibi. (2017). Manajemen Obat di Rumah Sakit. Yogyakarta: Gadjah Mada University Press. 
Somantri, A. P. (2013). Evaluasi Pengelolaan Obat di Instalasi Farmasi Rumah Sakit "X". Skripsi; Fakultas Farmasi Universitas Muhammadiyah Surakarta, Surakarta.

Syahreni, D. (2016). Gambaran Penyebab dan Kerugian karena Obat Rusak dan Kedaluarsa di Apotek
Wilayah Kota Yogyakarta. Skripsi; Fakultas Farmasi Universitas Gadjah Mada, Yogyakarta.

Wati, W., Fudholi, A. \& Pamudji, G. (2013). Evaluasi Pengelolaan Obat dan Strategi Perbaikan Dengan Metode Hanlon di Instalasi Farmasi Rumah Sakit Tahun 2012. Jurnal Manajemen dan Pelayanan Farmasi; 3; 283-290. 